\title{
Solar Energy Harvester for Wireless Sensor Networks
}

\author{
P Srinivas ${ }^{1}$, K Vijaya Lakshmi ${ }^{2}$ \\ Associate Professor, Dept. of EIE, VR Siddhartha Engineering College, Vijayawada, India ${ }^{1}$ \\ Assistant Professor, Dept. of EIE, VR Siddhartha Engineering College, Vijayawada, India ${ }^{2}$
}

\begin{abstract}
Wireless Sensor Networks (WSNs) are employed today in many application areas, ranging from health and lifestyle to automotive, smart building, predictive maintenance, active RFID tags. The commercially available sensor nodes are battery-driven devices. As days proceed, the batteries used in the nodes losses their charge and subsequently get isolated from the network. Energy harvesting and management is the most convenient ways to solve the problem of making WSN autonomous and enable widespread use of these systems in many applications. Out of various energy sources, solar radiation energy is available everywhere and fulfil the power requirement of WSN. Thus, a solar energy harvester for low powered wireless sensor networks is proposed. In this paper, a solar energy harvester which composed of a solar panel and energy harvesting module is introduced. This scheme works on the principle of photo voltaic effect. Harvested energy is used to charge the EnerChip batteries in the EH module, which is used to communicate the integrated temperature and RF signal strength information of environment at end point or WSN to the access point.
\end{abstract}

Keywords: WSN, EnerChip EH Module, Boost converter, Rechargeable storage batteries, PV system.

\section{INTRODUCTION}

Wireless sensor network (WSN) is the second largest network after the Internet in the world, and it ranks as the first of the next ten emerging technologies. Currently, it has been used widely in the Internet of Things (IOT), mainly for environmental parameter monitoring in various production circumstances, such as greenhouse $[1,2]$, water quality monitoring $[3,4]$ and so on. The most up-to-date power density of available battery technology cannot match the needs of most WSN for long lifetime and small form factor, which limits the use of WSN due to the need for large batteries. Energy harvesting and management may be the most convenient ways to solve the problem of making WSN autonomous and enable widespread use of these systems in many applications [5].

Conventionally, ordinary batteries can be considered as power source in WSN, where researchers have made efforts to save the finite battery on power control by routing algorithm and topology optimization [6- 8]. On the other hand, reducing the energy consumption of the nodes always sacrifices performances like computing. The most up-to-date power density of available battery technology cannot satisfies the needs of most WSN for long lifetime and small form factor, which limits the use of WSN due to the need for large batteries. It also has a possibility that the efficient batteries for small devices will become available in future. Energy harvesting and management may be the most efficient ways to solve the problem of making WSN autonomous and enable wide spread use of these systems in many applications [9]. The state-of-the-art energy-storage techniques for energy-harvesting systems in sustainable WSNs can be classified into two technologies, i.e., super capacitors and rechargeable batteries [10]. These two categories have their own advantages and disadvantages, involving energy-storage density, lifetime, discharging, leakage, size and so on [11]. Since the super capacitors have significantly lower power density and higher leakage overhead than rechargeable batteries [12], which makes them impractical for small-package WSN nodes, we employ an energy-harvesting system using a lithium battery as the storage.

From the electrochemical theory, we may learn that the aging of the lithium battery is influenced greatly by the self state of charge (SOC) [13-15]. Data from [16] show that lithium batteries in high SOC are more vulnerable to environmental impacts of aging and SOC cycling the batteries enhances the resistive lives. Therefore, it must be avoided that the battery always be in high SOC to extend battery lifetime, and approaches, one example of which is recharging the battery until its voltage drops below a specific level, should be taken [17]. The charging managements are usually employed by microcontrollers for the flexibility of software designing and implementation [10,18], but researchers [19] have proven that battery-charging controlled by software may have some problems in which charging logic could not work, and that the battery could not be charged under sufficient sunlight. In our system, the charging management is implemented by hardware instead of the codes running within the microcontroller for consideration of reliability. 
This paper focuses on a solar energy harvester which composed of a solar panel and energy harvesting module and works on the principle of photo voltaic effect. This harvested energy is used to charge the EnerChip batteries in the EH module. The battery supplies sufficient power to WSN to communicate the integrated temperature and RF signal strength information of environment at end point or WSN to the access point.

A. Block Diagram of Energy Harvester for WSN

A block diagram of Solar Energy Harvester Module is shown in Fig.1 which consists of

$>$ Input Power Transducer

$>$ Boost Converter

$>$ Charge Controller

$>$ Rechargeable Energy storage batteries (EnerChip CBC050)

$>$ Power Management Block

$>$ Wireless Sensor Network

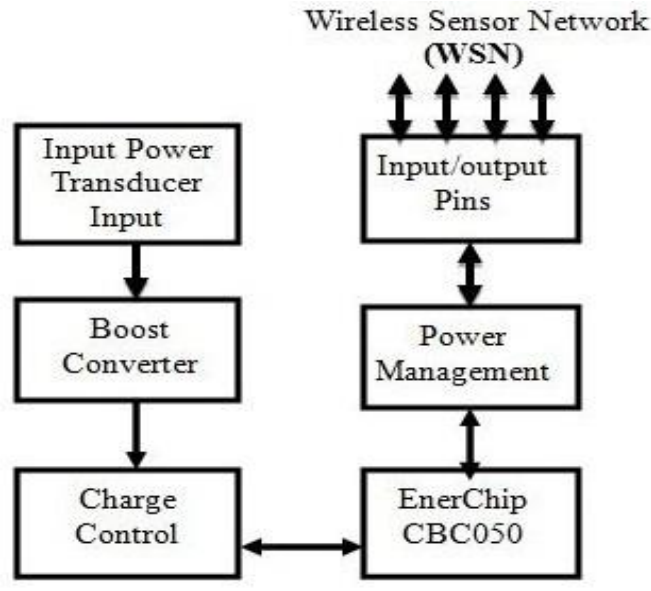

Fig.1. Block diagram of Energy Harvester for WSN

1. Input Power Transducer

CBC5300 will operate with many transducer types. The CBC5300 module is designed to work with transducers having output impedance over the range of $58 \Omega$ to $4 \mathrm{k} \Omega$ and an input voltage range of $270 \mathrm{mV}$ to $1.5 \mathrm{~V}$. The minimum open circuit voltage to start operation is $700 \mathrm{mV}$. The available input power transducers are solar panels, wind turbines, thermoelectric generators, piezoelectric transducers etc.

\section{Boost Converter}

A boost converter is used to increase the voltage from the solar cell to a sufficient level to charge the thin-film battery and run the rest of the system. A boost converter (step-up converter) is a DC-to-DC power converter that steps up voltage (while stepping down current) from its input (supply) to its output (load). It is a class of switched-mode power supply (SMPS) containing at least two semiconductors (a diode and a transistor) and at least one energy storage element, a capacitor, inductor, or the two in combination. To reduce voltage ripple, filters made of capacitors (sometimes in combination with inductors) are normally added to such a converter's output (load-side filter) and input (supply-side filter) [20].

\section{Charge Controller}

The Charge Control block continuously monitors the output of the boost converter. If the output of the boost converter falls below the voltage needed to charge the EnerChip, the charge controller disconnects the boost converter from the system to prevent back powering the boost converter in low light conditions.

\section{Power Management Block}

The Power Management block prevents the EnerChip from discharging too deeply in low-light conditions or under abnormally high current loads. It also ensures that the load is powered up with a smooth power-on transition. The Power Management block has a control line, CHARGE, which indicates to the MSP430 that the solar energy harvester is actively charging the EnerChip. The control line input, BATOFF, is available for the MSP430 to isolate itself from the EnerChip to conserve battery life in prolonged low-light conditions. 


\section{Rechargeable Storage Batteries (EnerChip CBC050)}

The Energy Harvesting Module features two EnerChip batteries mounted on the board with a 100-mAhr capacity and a $1,000-\mathrm{mF}$ capacitor for high-current pulses during wireless transmissions. Using the power management status and control signals on the SEH-01, the firmware on the MSP430 has been written to make the application 'Energy Aware' to maximize the overall lifetime of the system [21].

\section{Wireless Sensor Networks}

A WSN usually consists of tens to thousands of such nodes that communicate through wireless channels for information sharing and cooperative processing. WSNs can be deployed on a global scale for environmental monitoring and habitat study, over a battle field for military surveillance and reconnaissance, in emergent environments for search and rescue, in factories for condition based maintenance, in buildings for infrastructure health monitoring, in homes to realize smart homes, or even in bodies for patient monitoring [22].

\section{ENERGY HARVESTING TECHNIQUES}

\section{A. Introduction}

Energy harvesting techniques are being investigated as means to convert an indirectly usable form of energy to electrical energy sufficient to power unattended or inaccessible, and usually low power systems. Examples of such systems are wireless sensors, biomedical implants, military monitoring devices, structure-embedded instrumentation, remote weather station, calculators, watches, Bluetooth headsets. Recently, Nokia announced it is developing a mobile prototype that could harvest energy from ambient radio waves emitted from mobile antennas, TV masts and other sources [23-27]. Energy harvesting technique used in this paper is solar energy because it is easily available throughout the world.

\section{B. Solar Energy}

A solar cell, or photovoltaic cell, is an electrical device that converts the energy of light directly into electricity by the photovoltaic effect. It is a form of photoelectric cell, defined as a device whose electrical characteristics, such as current, voltage, or resistance, vary when exposed to light. Solar cells are the building blocks of photovoltaic modules, otherwise known as solar panels.

When the PV cell is placed in the sun, the radiant energy energizes the free electrons. If a circuit is made by connecting the top and bottom of the silicon wafer with wire, electrons flow from the n-type through the wire to the p-type. The PV cell is producing electricity-the flow of electrons. If a load, such as a light bulb, is placed along the wire, the electricity will do work as it flows. The conversion of sunlight into electricity takes place silently and instantly. There are no mechanical parts to wear out. Various photovoltaic technologies and materials used to manufacture each cell are given in the below table. There many commercially available solar cell technologies. The name of the technology comes from materials used in making solar cells [23].

\section{TABLE I COMMERCIAL SOLAR CELL TECHNOLOGIES, MATERIALS AND EFFICIENCY}

\begin{tabular}{|c|c|c|c|}
\hline Solar Photo Voltaic Technologies & Solar Cell Type & Materials Used & Efficiency (\%) \\
\hline Crystalline Silicon(c-Si) solar cell & $\begin{array}{c}\text { Mono Crystalline Silicon } \\
\text { Poly (or) Multi } \\
\text { Crystalline Silicon }\end{array}$ & $\begin{array}{c}\text { Mono Crystalline Silicon } \\
\text { Multi Crystalline Silicon }\end{array}$ & $14-16$ \\
\hline Thin Film Solar Cell & $\begin{array}{c}\text { Amorphous Si (a-Si) } \\
\text { Cadmium } \\
\text { telluride(cdTe) } \\
\text { Copper-Indium-Gallium-16 } \\
\text { Selenide(CIGS) }\end{array}$ & $\begin{array}{c}\text { Amorphous Silicon } \\
\text { Cadmium and Tellurium } \\
\text { Copper, Indium, Gallium, } \\
\text { Selenide }\end{array}$ & $8-11$ \\
\hline Multi Junction Solar Cell & $\begin{array}{c}\text { GaInP/GaAs/Ge } \\
\text { Gallium, Indium } \\
\text { Phosphide/Gallium } \\
\text { Arsenide/Germanium }\end{array}$ & $\begin{array}{c}\text { Gallium(Ga), Arsenic(Ar), } \\
\text { Indium(In), } \\
\text { Phosphorous(P), } \\
\text { Germanium(Ge) }\end{array}$ & $8-11$ \\
\hline
\end{tabular}

From the table I, we notice that the efficiency of the solar cell varies from one technology to another technology. 
UGC Approved Journal

IJIREEICE

\section{International Journal of Innovative Research in} Electrical, Electronics, Instrumentation and Control Engineering

\section{ISO 3297:2007 Certified}

Vol. 5, Issue 6, June 2017

\section{SOLAR ENERGY HARVESTING MODULE}

\section{A. Introduction}

The EnerChip EH CBC5300 is a self-contained Energy Harvesting power module in a 24-pin DIP configuration. The CBC5300 module is designed to accept a wide range of energy transducer inputs, store the harvested power, and deliver managed power to the target system. The purpose of this module is to enable system designers to quickly develop Energy Harvesting applications [28].

\section{B. System Description}

The schematic of the EnerChip EH CBC5300 energy harvesting module is shown in Fig.2. has two CBC050 50 $\mu$ Ah EnerChip rechargeable battery cells, for a total $100 \mu \mathrm{Ah}$ of capacity.

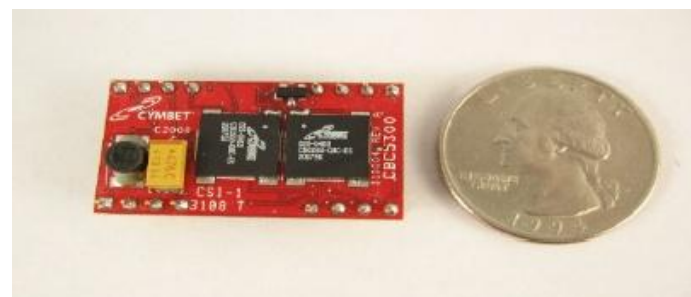

Fig.2. EnerChip EH Module - CBC5300

The energy harvesting transducer (e.g. photovoltaic cell, piezoelectric material, thermoelectric converter, etc.) converts ambient energy into electrical energy. The output voltage of the energy harvesting transducer is often too low to charge the EnerChip batteries and power the rest of the system directly, so a boost converter is used to boost the energy harvesting transducer voltage to the voltage needed to charge the EnerChip and/or power the system.

\section{WIRELESS SENSOR NETWORKS}

Due to the advantages of low cost, high flexibility and ease of maintenance, WSNs are especially suitable for large scale deployments in various environments [29]. Therefore, they can be applied to many different applications including habitat monitoring, vehicle tracking, and structural monitoring, etc. [30].

\section{A. WSN Architecture}

Fig. 3 shows the architecture of wireless sensor network. WSN system leverages the power of wireless to connect with multiple sensors to single user interface. The WSN system acts as a data acquisition and smart control over various sensors. WSN is an outdoor wireless system for applications like home automation, smart agriculture, smart city, industrial control, AMR, Smart Energy and more. The WSN system has Zigbee/Bluetooth/Wi-Fi Nodes, Gateway and Router. The system allows access to the sensors from remote online locations over internet.

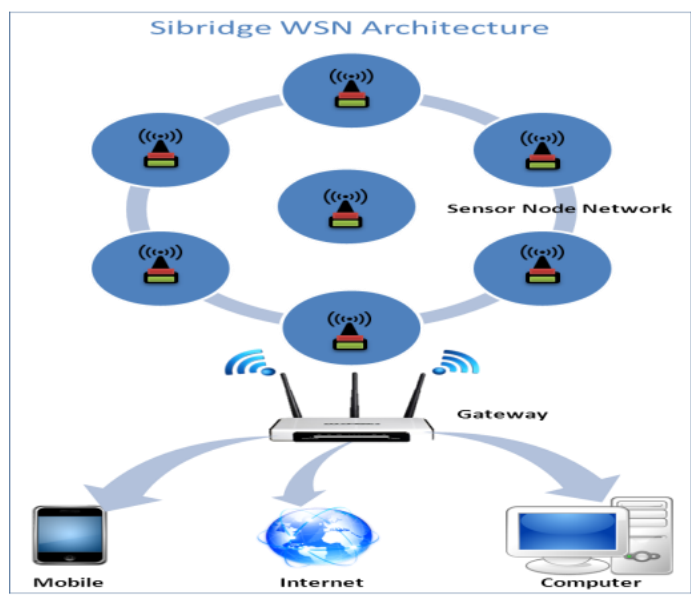

Fig.3. WSN Architecture

WSN node has sensors or actuators which can be monitored or controlled through wireless interfaces like Wi-Fi, Bluetooth or Zigbee.WSN node is a small, very low power and low cost module that can work independently or can 
connect with one or more nodes easily. WSN node is modular such that it can be configured for different wireless interfaces, sensors, and actuators.WSN programming carries the following benefits, topologies and modes [30].

B. Communication In A WSN

The well-known IEEE 802.11 family of standards was introduced in 1997 and is the most common wireless networking technology for mobile systems. It uses different frequency bands, for example, the 2.4-GHz band is used by IEEE 802.11b and IEEE 802.11g, while the IEEE 802.11a protocol uses the 5-GHz frequency band. IEEE 802.11 was frequently used in early wireless sensor networks and can still be found in current networks when bandwidth demands are high (e.g., for multimedia sensors). However, the high-energy overheads of IEEE 802.11-based networks make this standard unsuitable for low-power sensor networks. Typical data rate requirements in sensor networks are comparable to the bandwidths provided by dial-up modems, therefore the data rates provided by IEEE 802.11 are typically much higher than needed.

\section{SOFTWARE}

Two different development software tools for the MSP430 are available from TI: IAR Embedded Workbench Kick Start and Code Composer Studio (CCS). The term "Kick Start" refers to the limited version of Embedded Workbench that allows up to $4 \mathrm{~KB}$ of $\mathrm{C}$-code compilation.

The eZ430-RF2500 shown in fig.4 is a complete USB-based MSP430 wireless development tool providing all the hardware and software to evaluate the MSP430F2274 microcontroller and CC2500 2.4GHz wireless transceiver.

The eZ430-RF2500 uses the IAR Embedded Workbench Integrated Development Environment (IDE) or Code Composer Studio $^{\mathrm{TM}}$ (CCS) IDE to write, download, and debug an application. The eZ430-RF2500T target board is an out-of-the box wireless system that may be used with the USB debugging interface, as a stand-alone system with or without external sensors, or may be incorporated into an existing design. The USB debugging interface enables the eZ430-RF2500 to remotely send and receive data from a PC using the MSP430 Application UART.

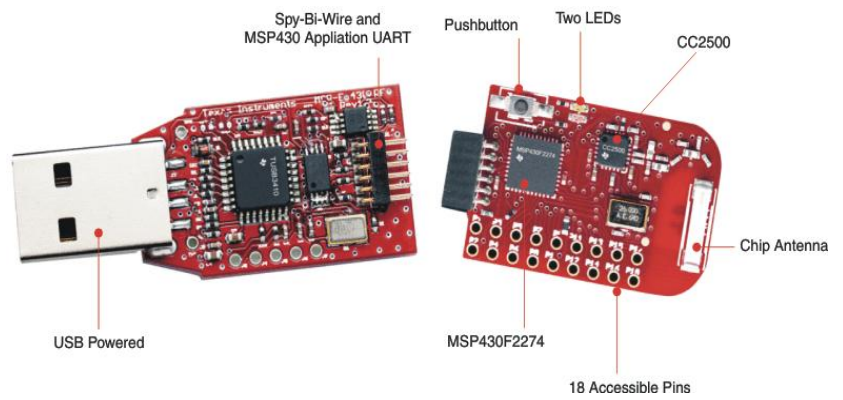

Fig.4. eZ430-RF2500

The hardware includes:

- Two eZ430-RF2500T target boards

- One eZ430-RF USB debugging interface

- One AAA battery pack with expansion board (batteries included)

The eZ430-RF2500 can be used as a stand-alone development tool. Additionally, the eZ430-RF2500T target board also may be detached from the debugging interface and integrated into another design by removing the plastic enclosure. The target board features an MSP430F2274 and most of its pins are easily accessible.

A. Software Installation

Two different development software tools for the MSP430 are available from TI: IAR Embedded Workbench Kick Start and Code Composer Studio (CCS). The term "Kick Start" refers to the limited version of Embedded Workbench that allows up to $4 \mathrm{~KB}$ of C-code compilation. The SimpliciTITM network protocol is a proprietary, low-power radiofrequency (RF) protocol targeting simple, small RF networks ( $<100$ nodes).

\section{RESULTS}

The Sensor Monitor PC application is a graphical representation of the star network and displays the sampled data from each wireless device. The center node is the Access Point and the attached nodes are the End Devices, which display 
UGC Approved Journal

IJIREEICE

International Journal of Innovative Research in Electrical, Electronics, Instrumentation and Control Engineering

\section{ISO 3297:2007 Certified}

Vol. 5, Issue 6, June 2017

their temperature, voltage, and their transmission frequency. The number of End Devices can be expanded by adding more wireless nodes to the network.

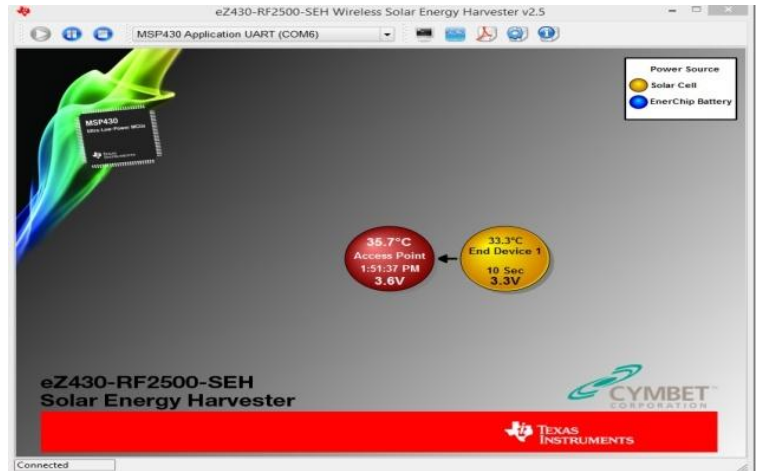

Fig.5. WSN data displayed at access point

As the target board connected to the solar harvesting module, a node will connect to the access point on the desktop as shown in fig.5. The colour of the node will be in yellow, if it is taking power from light source or it will be blue, if it is running by battery power. The distance between the node (End device) and the access point is less which indicates area were the node is located. It also provides the temperature at the end device and the access point. The time representing on the node gives the transmitting frequency.

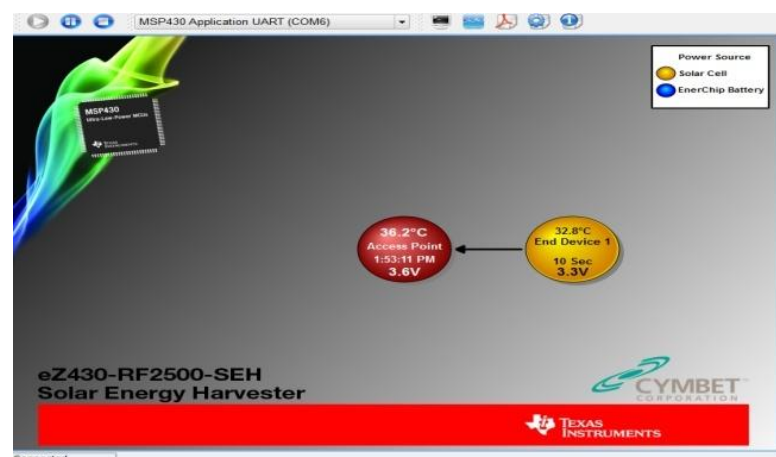

Fig.6. WSN data displayed with increased distance from access point

Fig. 6 shows that the distance of end device is increased which decreases temperature at end point.

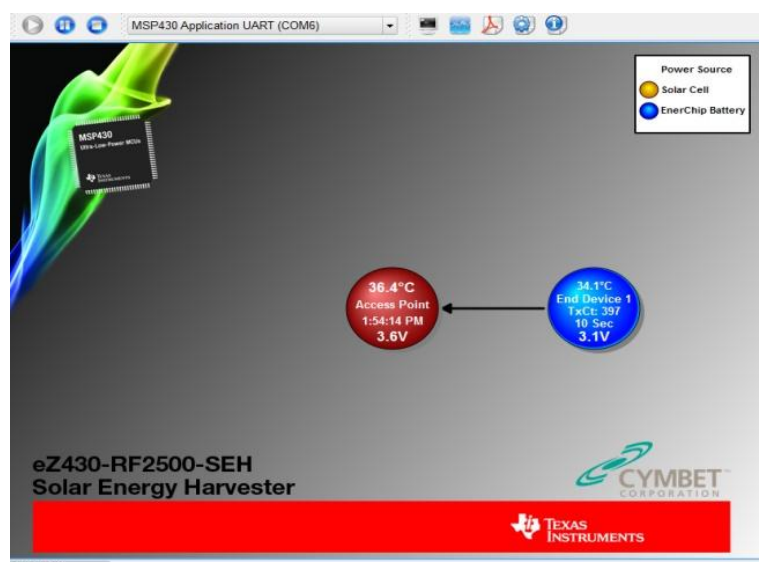

Fig.7. WSN data displayed when node powered with battery

Fig.7 shows the input from the transducer is not sufficient to drive the WSN. So, the node (End device) works on battery power, which is identified when the node is blinking in blue colour.

Fig. 8 shows the signal strength from the access point and temperature at the access point. Since the signal from access point is received through USB there is no variation in it. 
UGC Approved Journal

IJIREEICE

\section{International Journal of Innovative Research in} Electrical, Electronics, Instrumentation and Control Engineering

ISO 3297:2007 Certified

Vol. 5, Issue 6, June 2017

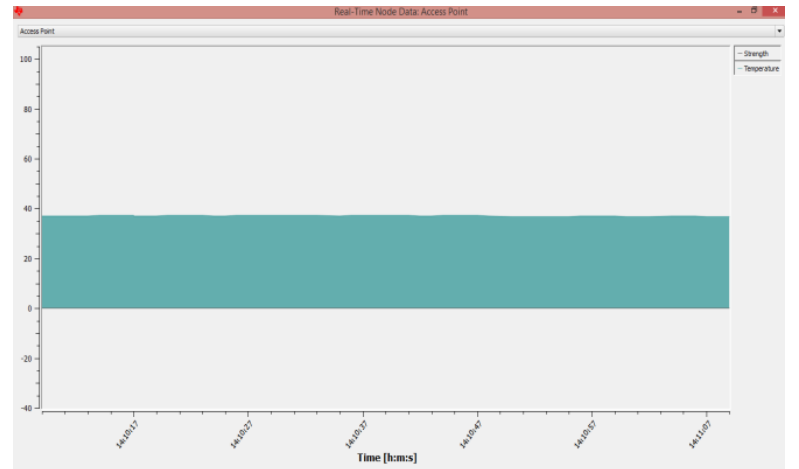

Fig.8. Signal strength at access point which receives power from PC

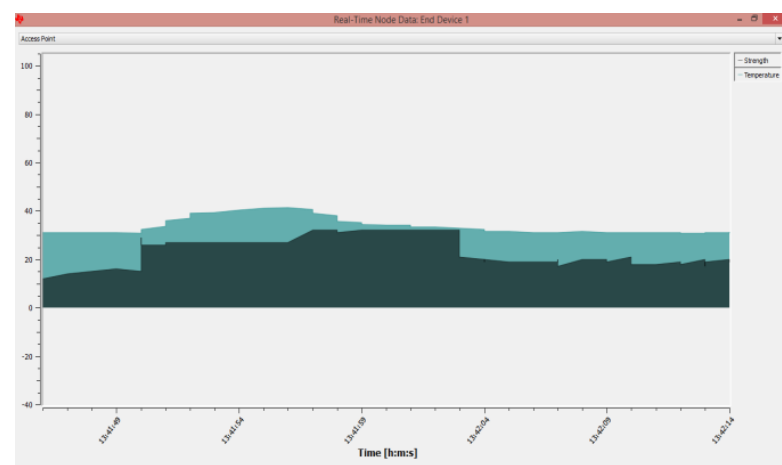

Fig.9. Signal strength at end point or WSN

Fig.9 shows the temperature and signal strength of the End device or WSN. Since the readings are taken at different locations signal strength and temperature is varied.

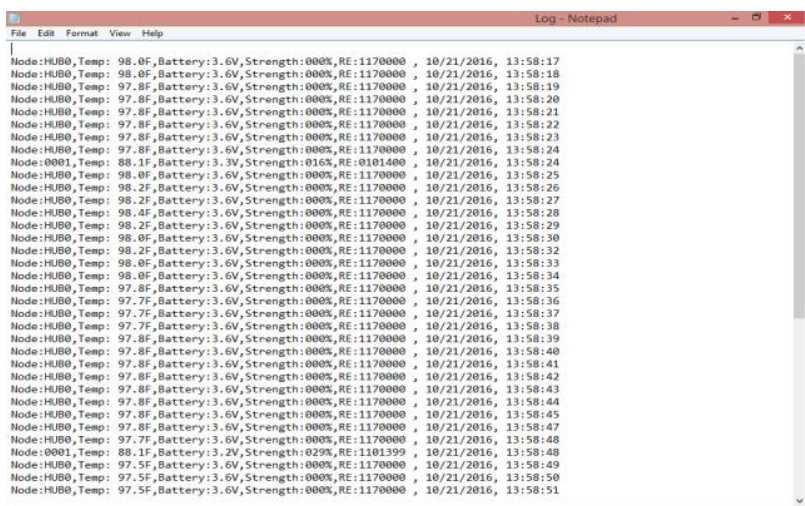

Fig.10. Data logging from various WSNs

Fig.10 shows the console window which is used to view the real-time data of all nodes in text format.

\section{CONCLUSION}

In this paper, a novel intelligent solar energy-harvesting system is developed and information at WSN is monitored from the access point. The solar energy harvester module includes a high-efficiency solar panel (2 1/4 x 2 1/4-inch) optimized for operating indoors under low-intensity lights, which provides enough power to run a low-power wireless sensor application. The system also manages and stores additional energy in a pair of thin-film rechargeable EnerChips, capable of delivering enough power at $3.5-3.6 \mathrm{~V}$ based on load current to drive WSN and for more than 400 transmissions from a single charge. The eZ430-RF2500 is a complete USB-based MSP430 wireless development tool, providing all of the hardware and software necessary to use the MSP430F2274 microcontroller and CC2500 2.4-GHz wireless transceiver. With this hardware and software integrated temperature and RF signal strength indicators monitored the environment at WSN from access point. 


\section{International Journal of Innovative Research in Electrical, Electronics, Instrumentation and Control Engineering}

\section{ISO 3297:2007 Certified}

Vol. 5, Issue 6, June 2017

\section{REFERENCES}

[1] ZhouY, Yang X, Guo X, et al. A design of greenhouse monitoring \& control system based on ZigBee wireless sensor network. IEEE. Int. Conf. WiCOM, (IEEE, Shanghai, 2007), pp. 2563-2567

[2] Ahonen T, Virrankoski R, Elmusrati M. Greenhouse monitoring with wireless sensor network. IEEE/ASME. Int. Conf. on MESA, (IEEE/ASME, Beijing, 2008), pp. 403-408

[3] Nasser N, Zaman A, Karim L, et al. CPWS: An efficient routing protocol for RGB sensor-based fish pond monitoring system. IEEE. 8th. Int. Conf. WiMob, (IEEE, Barcelona, 2012), pp. 7-11

[4] O'Flyrm B, Martinez R, Cleary J, et al. Smart Coast: a wireless sensor network for water quality monitoring. IEEE. 32nd. Conf. LCN. 2007;815-816.

[5] RJM Vullers, RV Schaijk, HJ Visser et al., Energy harvesting for autonomous wireless sensor networks. IEEE. Solid State Circuits. Mag. 2(2), 29-38 (2010)

[6] GS Arumugam, T Ponnuchamy, EE-LEACH: development of energy-efficient LEACH Protocol for data gathering in WSN. EURASIP. J. Wireless. Commun. Netw. 1, 76 (2015).

[7] I Butun, I Ra, R Sankar, PCAC: power-and connectivity-aware clustering for wireless sensor Networks. EURASIP. J. Wireless. Commun. Net. 1, 83 (2015).

[8] G Anastasi, M Conti, M Di Francesco et al., Energy conservation in wireless sensor networks: a survey. Ad. Hoc. Netw. 7(3), 537-568 (2009)

[9] RJM Vullers, RV Schaijk, HJ Visser et al., Energy harvesting for autonomous wireless sensor networks. IEEE. Solid State Circu its. Mag. 2(2), 29-38 (2010)

[10] F Akhtar, MH Rehmani, Energy replenishment using renewable and traditional energy resources for sustainable wireless sensor networks: a review. Renew. Sustain. Energy Rev. 45, 769-784 (2015)

[11] VA Boicea, Energy storage technologies: the past and the present. Proc. IEEE. 102(11), 1777-1794 (2014)

[12] Z Xu et al., Electrochemical supercapacitor electrodes from sponge-like graphenenano architectures with ultrahigh power density. J. Phys. Chem. Lett. 3(20), 2928-2933 (2012)

[13] W Waag, S Käbitz, DU Sauer, Experimental investigation of the lithium-ion battery impedance characteristic at various conditions and aging states and its influence on the application. Appl. Energy. 102, 885-897 (2013)

[14] M Broussely, P Biensan, F Bonhomme et al., Main aging mechanisms in Li ion batteries. J. Power. Sources. 146(1), 90-96 (2005)

[15] J Vetter, P Novák, MR Wagner et al., Ageing mechanisms in lithium-ion batteries. J. Power. Sources. 147(1), 269-281 (2005)

[16] M Ecker, JB Gerschler, J Vogel et al., Development of a lifetime prediction model for lithium-ion batteries based on extended accelerated aging test data. J. Power. Sources. 215, 248-257 (2012)

[17] Jiang X, Polastre J, Culler D. Perpetual environmentally powered sensor networks. IEEE. 4th. Int Symp. IPSN, (IEEE, Los Angeles, 2005), pp. 463-468

[18] Xiang Y, Pasricha S. Run-time management for multicore embedded systems with energy harvesting. 2015.

[19] Dutta P, Hui J, Jeong J, et al. Trio: enabling sustainable and scalable outdoor wireless sensor network deployments. Proc. 5th. Int. Conf. Info. Process. Sensor. Netw, (ACM, Nashville, TN, 2006), pp. 407-415

[20] https://en.wikipedia.org/wiki/Boost_converter.

[21] http://www.cymbet.com/products/solid-state-batteries/cbc050-m8c.php

[22] http://www.worldscibooks.com/compsci/6288.html

[23] W. Achim, R. Mauricio, M. David, M. Stefan, R. Nils and J. Ulrike, "Monitoring Of Photovoltaic Systems: Good Practices and Systematic Analysis," 4102013.

[24] AwangJusoh, ToleSutikno, TanKazGuan and SaadMekhilef, "A Review on Favorable Maximum Power Point Tracking Systems in Solar Energy Applications" Telkomnika,Vol.12,No.1,March 2014,pp.6-22.

[25] A.K.Mukerjee, Nivedita Thakur, "Photovoltaic Systems Analysis \& Design",211,PHI Learning Private Limited,Delhi-110091.

[26] T.Esram, P.L. Chapman. Comparison of Photovoltaic Array Maximum Power Point TrackingTechniques.IEEE Transactions on Energy Conversion. 2007; 22(2): 439-449.

[27] M.S.aitCheikh*,C.Larbes*,G.F.TchoketchKebir and A.Zerguerras, "Maximum Power Point tracking using a fuzzy logic control scheme",Revue des Energies Renouvelables Vol.10 N³(2007) 387-395,(recu le 20 April 2007-accepte le 25 September 2007).

[28] http://www.cymbet.com/pdfs/DS-72-06.pdf

[29] I.F. Akyildiz, W. Su, Y. Sankarasubramaniam, E. Cayirci, 2002,IEEE Communications Magazine.

[30] http://www.sibridgetech.com/Wireless-Sensor-Network.aspx

\section{BIOGRAPHIES}

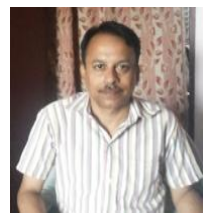

Paruchuri Srinivas was born in Andhra Pradesh, India, in 1970. He received the M.Tech. degree in Electronic Instrumentation from NIT Warangal, India, in 1992.

In 1993, he joined the Department of Electrical and Electronics Engineering, VR Siddhartha Engineering College, Vijayawada, as a Lecturer and currently he is an Associate Professor in Electronics \& Instrumentation Engineering in the same college. He has 20 years of teaching experience and a number of technical publications in peer reviewed journals. His current research interests include control systems and optimization techniques. He is a Life Member of Indian Society technical Education (ISTE), the Instrument Society of India (ISOI) and the Biomedical Engineering Society of India (BMESI).

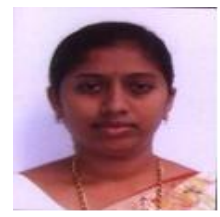

Kodali Vijaya Lakshmi was born in Visakhapatnam, India, in 1982. She received the B.Tech degree in Instrumentation Technology from VR Siddhartha Engineering College, Vijayawada, India, in 2003, and the M.Tech. degree in Industrial Process Instrumentation from the Andhra University, Visakhapatnam, India, in 2006. In 2006, she joined the Department of Electronics and Instrumentation Engineering, VR Siddhartha Engineering College, Vijayawada, as a Lecturer and currently she is an Assistant Professor. She has 9 years of teaching experience and a number of technical publications in peer reviewed journals. Her current research interests include process control, process modelling and simulation, neural networks and optimization techniques. Mrs. Kodali is a Life Member of the Instrument Society of India (ISOI) and the Biomedical Engineering Society of India (BMESI). 